\title{
ALGUNOS APUNTES, DE UN AMIGO, SOBRE EL SIGNIFICADO DE JAVIER Y SU OBRA PARA EL URBANISMO ESPAÑOL.
}

\author{
Luciano Parejo Alfonso \\ Luciano Parejo Alfonso \\ Catedrático de Derecho Administrativo \\ Universidad Carlos III de Madrid \\ Madrid, España
}

Remisión Artículo: 29-1-2007

Palabras Claves: Ordenación territorial, Derecho de propiedad, Perspectiva histórica del Urbanismo, Singularidad del Urbanismo español, Urbanismo comparado, Evaluación ambiental estratégica.

En Javier obra y persona van unidas. Disciplinó su humanidad cálida, generosa y desbordante en una enorme capacidad de trabajo que, servida por una penetrante inteligencia, volcó -para satisfacer su vocación social, de mejora del mundo en el que le tocó vivir- esencialmente en el urbanismo (mejor sería decir, la ordenación del territorio en general y de la ciudad en particular).

Desde su formación en la arquitectura, pero desbordándola en un esfuerzo autodidacta plenamente conseguido, logró realizar en este campo una contribución decisiva no sólo en los órdenes de la clarificación, la depuración, la sistematización y también la difusión, sino, sobre todo, de la innovación y el progreso de las técnicas y las instituciones. Nada más lejos de la exageración que la afirmación de que el urbanismo español de hoy no puede entenderse al margen de su obra.

Es obvio, pero quiero recordarlo, porque -precisamente por la fortaleza de la personalidad y el valor de la opinión- ni la persona, ni las posiciones mantenidas por Javier dejaron -dejan aúnindiferentes y suscitaron -suscitan aún- controversia, que estas líneas se escriben desde la amistad, la admiración y la plena sintonía con la perspectiva, el planteamiento básico y los objetivos fundamentales que presidieron la vida y tarea de Javier. Importa, por ello, destacar la que yo creo la clave de su quehacer: la curiosidad intelectual insaciable y su alimentación por un afán apasionado por el verdadero saber que, trascendiendo las apariencias de los fenómenos, tal como éstos se nos presentan, aspira a penetrar -a través de la interconexión de sus diversas manifestaciones- la identidad de dichos fenómenos y alcanzar, por tanto, el conocimiento capaz de sustentar una cabal teoría sobre el urbanismo como un todo.

Se entiende así la preocupación por la dimensión histórica, el esfuerzo por penetrar la forma para llegar al fondo y la apertura a otras disciplinas, en particular la economía y el Derecho. 
Y también el enorme esfuerzo, ya en la madurez y con ocasión del trabajo de investigación que le condujo a la obtención del máximo grado académico -el de doctor-, por sentar las bases de la ciencia comprensiva e interdisciplinar que el bautizó como <<coranomía>>.

Punto de arranque, motivo basal y palanca fundamental acabó siendo en Javier, primero la peculiaridad de institutos y técnicas ensamblados en el completo, complejo y trabado sistema legal de la Ley del Suelo de 1956, sobre cuyas raíces históricas llamó su atención la obra de M. Bassols Coma; y luego ya, definitivamente, la comprobación de la singularidad -y no sólo tomando como referencia comparativa nuestro entorno continental inmediato- de la entera respuesta institucional a la cuestión radical de la ocupación del territorio y su <<arreglo>> , en particular en forma de ciudad, de medio urbano, como soporte y marco de la vida.

\section{La perspectiva histórica: de la peculiaridad del urbanismo, derivada de sus orígenes, a su adaptación a las exigencias del presente.}

La perspectiva histórica se alimenta de una investigación preocupada por desentrañar el contexto económico-social e institucional del surgimiento y la decantación de las técnicas y las instituciones urbanísticas, que ni siquiera desatiende la circunstancia $e$, incluso, las motivaciones de los actores principales en tales procesos.

Esta investigación, que, como se ve, va más allá del análisis de las respuestas y soluciones formalizadas en normas y su evolución -a la que solemos circunscribirnos los juristas urbanistas-, desbordó ampliamente el esfuerzo personal de Javier, pues -con el empeño característico que ponía en cuanto hacía- la incorporó a las líneas de trabajo que impulsó en los cargos públicos que desempeñó (muy especialmente al frente del Centro de Estudios Urbanos del entonces Instituto de Estudios de Administración Local) y la contagió a cuantos alumnos que debían hacer algún trabajo o elaborar su tesis doctoral- lograba convencer su entusiasmo.

Aunque hubo de registrar la frustración de alguna de sus iniciativas, entre las que -según mi memoria recuerda- la que más le afectó fue el nulo eco que obtuvo para su proyecto de rescate del acervo de actuaciones en materia de reforma y colonización agrarias, los logros en el terreno que vengo comentando son dignos de ser resaltados. Además del descubrimiento en archivos de trabajos originales -como, en particular, algunos de Ildefonso Cerdá- y el recordatorio y la precisión del papel de P. Madoz en este campo más allá de su conocida aventura en la promoción inmobiliaria (especialmente en su corta trayectoria como Gobernador de Barcelona y sin descuidar su relación personal con Cerdá), merece destacarse la reivindicación de nuestro papel pionero -gracias a la figura de Cerdá- en el contexto europeo, que luce en la acuñación misma del concepto <<urbanismo>>.

Gustaba Javier llamar la atención sobre la visión de la relación con el territorio expresada en la aludida acuñación conceptual y que ha sido determinante de la evolución de nuestro urbanismo: el enfoque desde y para lo urbano (su expansión), erigido así en centro de gravedad y objetivo final (con la consecuencia de su específica autónoma eficacia legitimante de la ocupación y transformación del suelo). Y ello, desde la compatibilidad de la orientación impresa en origen por tal carga interior con una vocación significante expansiva del concepto 
(hasta alcanzar la entera ordenación territorial), en la que encuentra explicación tanto la tardía independendización entre nosotros de la visión estratégica y amplia del territorio y, por tanto, de la también tardía decantación de la <<ordenación del territorio>> (el amenagement du territoire francés, la Raumordnung alemana), como la dificultad para el despliegue y la operatividad funcional efectivos de ésta hasta nuestros días y, más aún, para el desarrollo y el juego plenos de las técnicas y los mecanismos adecuados para un verdadero y completo <<arreglo>> del territorio (más allá de la creación o regeneración de tejido urbano o de la ocupación para uso típicamente urbano o equivalente a él).

La eficacia de esta aproximación a nuestro urbanismo para la correcta identificación e inteligencia de sus claves, principios, instituciones y técnicas no precisa ponderación alguna, por ser evidente.

Baste con destacar como ilumina tanto la construcción sobre la idea del $<<$ proceso urbanizador y edificatorio > como una secuencia basada en una planificación previa y el sentido, alcance y las consecuencias de la misma para la elección de técnicas y su articulación en sistema, como también la persistencia de la eficacia constructiva, articuladora y orientadora de dicha idea no obstante la ruptura de la unidad de la formalización legal de la política urbanística.

Según creo, la plena conciencia de la singularidad del urbanismo español y la percepción de todas sus consecuencias, así como la progresiva experimentación de éstas como precisadas de corrección o, incluso, superación -especialmente en punto a la limitación que comportan en la relación con el territorio y las posibilidades para el idóneo <<arreglo〉> de éste-, fue gestándose en Javier lentamente a lo largo de su dedicación a los graves problemas que, ya en una sociedad en aceleradísima transformación por su plena integración en el curso de la comunitaria-europea, planteaba el urbanismo en sus dos caras fundamentales: la gestión en el tejido urbano de nueva creación o sujeto a reforma interior y el tratamiento del suelo excluido de la ocupación y transformación <<urbanística>>.

En este último terreno, la posición de Javier sobre el tratamiento del suelo rústico o, significativamente, excluido de la urbanización (llamado por ello también <<no urbanizable>>) fue siempre clara y radical, sintetizándose en la lucha por la preservación de su carácter y la dedicación, por ello, a la disciplina urbanística, como en la búsqueda de un tratamiento técnico y legal adecuado de esta clase de suelo.

Sus más decididos esfuerzos innovadores se concentraron, sin embargo, en diseñar soluciones imaginativas y útiles para la gestión urbanística en sentido estricto <<dentro >> del sistema mismo y aprovechando sus potencialidades.

Los frutos, innovadores, de su contribución en este terreno quizás más conocidos se concretaron en la <<desmaterialización>> (desconexión de todo soporte físico) del llamado aprovechamiento urbanístico para su conversión en entidad virtual susceptible de tráfico jurídico, el desarrollo operativo del mecanismo de <<transferencia del aprovechamiento $>>$ y la conexión de lo uno y lo otro mediante la actualización operativa de las unidades de actuación o ejecución <<discontinuas>> y la apertura de margen para la verificación del principio de distribución equitativa de beneficios y cargas no de forma conjunta y de una vez, sino como resultado de un proceso desarrollado sucesivamente al hilo de las diferentes operaciones y sobre la base de la autonomía de la voluntad de los en ellas intervinientes. 
Pero hubo otras aportaciones de mejora, menos comentadas, pero igualmente significativas, realizadas ya en la época de plena madurez y en el contexto de preparación de soluciones para iniciativas legislativas, concretamente la que dio lugar a la vigente Ley del suelo madrileña de 2001.

Me parece que pueden ejemplificarse en la articulación de las dotaciones públicas (incluidas las de cesión obligatoria y gratuita) en las llamadas <<redes públicas >>, supramunicipales y municipales, de infraestructuras y equipamientos y servicios, con ampliación de las mismas a la vivienda de promoción o protección públicas (concebida como resultado de una política y servicio públicos). La finalidad perseguida no es otra que la de posibilitar una ordenación flexible y ajustada a las reales necesidades sociales desde el convencimiento que había ido afirmándose en Javier de la convencionalidad, rigidez e inadecuación tanto de la centralidad de la escala municipal ( $\mathrm{y}$, por tanto, del planeamiento general municipal), como de determinadas categorías y técnicas encauzadoras del proceso sustantivo de ordenación, especialmente -en lo que ahora interesa y dejando aparte el corsé que representa la clasificación legalmente tipificada del suelo- del binomio sistemas generales-sistemas locales. El juego de las redes públicas permite, en efecto, combinar planificación estratégica supramunicipal (propia de la ordenación del territorio) y planificación general municipal (base de la ordenación urbanística) y organizar adecuadamente la totalidad de la <<infraestructura $>>$ del tejido urbano. Haciendo esto último en términos que, al mismo tiempo, i) soslayan las restricciones indebidas impuestas por la clasificación del suelo, superan la necesidad de determinación de la supuesta naturaleza general o local de una dotación pública o colectiva (para estar exclusivamente a las características y función reales de ésta); ii) acaban con la desvirtuación o desdibujamiento de la categoría urbanístico-municipal <<sistema general >> por sucesiva inclusión en ella (vía, fundamentalmente, legislación sectorial) de todo tipo de infraestructuras y equipamientos públicos de lógica supramunicipal; y iii) prueban la compatibilidad del nuevo planteamiento con el establecido régimen urbanístico de la propiedad ligado al proceso urbanizador y edificatorio.

Por lo dicho, huelga decir que en todas las contribuciones aludidas opera ya igualmente el curso de la reflexión de Javier sobre la relación entre la función pública de ordenación urbanística y la propiedad del suelo, a la que seguidamente aludiré.

\section{La perspectiva interdisciplinar y su incidencia en la comprensión del sistema urbanístico}

La necesidad de comprensión de las instituciones y técnicas desde de sus raíces históricas iba pareja en Javier a la de interrogación de éstas desde el punto de vista de su funcionalidad actual y, por tanto, a la de trascender tanto la ocasionalidad de las manifestaciones evidentes de los fenómenos urbanísticos, como la lógica de la formalización del tratamiento jurídico de éstos, para identificar las necesidades y los intereses reales subyacentes a efectos de discernir los atendibles y dignos de protección. Se entiende así perfectamente su incursión en los campos del Derecho y la economía, en los que sorprendía la penetración y comprensión que de sus principios y lógica había logrado. Como jurista mantengo vivo el recuerdo del continuo estímulo que representaban las inquietudes y preguntas de Javier, en cuanto suscitaban dudas donde antes parecía haber certezas y forzaban la reflexión sobre posibilidades no exploradas o 
siquiera intuidas. El resultado era, al menos en el contexto de la larga y sólida relación de amistad que -basada en el afecto y el respeto mutuos- mantuvimos, un proceso de verdadera retroalimentación y enriquecimiento recíproco.

Donde ese proceso prendió primero y mejor fue en el terreno del derecho de propiedad del suelo. Conforme con el planteamiento que sobre éste se mantenía en las Lecciones de Derecho Urbanístico (escritas, a finales de la década de los años setenta del pasado siglo por mí en colaboración con E. García de Enterría, al que profesaba admiración), Javier emprendió una explicación y un desarrollo propios desde la estricta técnica urbanística. Estos acabaron fraguando en el carácter público e independiente de las determinaciones de la ordenación urbanística (edificabilidad y uso, es decir, aprovechamiento urbanístico), sin perjuicio de acotar -dada la organización de la apropiación, uso, disfrute y disposición del suelo, en principio y con carácter general, por el instituto de la propiedad privada- el contenido y alcance del interés cabalmente urbanístico de los propietarios correspondientes. El aprovechamiento urbanístico es, así y enteramente, un valor añadido al suelo por la acción urbanística del poder público. De donde la legitimidad de la determinación por la ordenación urbanística de los términos y las condiciones de la protección del interés de los propietarios, lo que quiere decir de los presupuestos para que éstos -en ejercicio del ius aedificandi- puedan materializar el pertinente aprovechamiento y, con ello, constituir en la realidad el soporte y el objeto ciertos y reales de la correspondiente situación tutelada por el Derecho por subsumible en el instituto de la propiedad privada.

Este planteamiento quedó acabado y perfilado muy tempranamente, ya a comienzos de la década de los años ochenta del pasado Siglo, mereciendo recuerdo la expectación que producían entonces las transparencias que proyectaba Javier en sus conferencias y en las que plasmaba muy gráficamente aquél. Y no sufrió ya, en lo sustancial, rectificación ulterior, proyectándose -como es fácilmente comprensible- sobre el tratamiento de los restantes aspectos del sistema urbanístico y, muy particularmente, en la valoración del suelo; materia, en la que la posición de Javier fue siempre consecuente $y$, por ello, radical en el plano de los principios, aunque atemperada, en el de la concreción de éstos, por los requerimientos -a los que no dejaba de ser sensible- que en la práctica resultan del entero sistema económico-social y se imponen a la formalización jurídica de las reglas de valoración objetiva.

Este entendimiento de la relación entre la ordenación urbanística (en tanto que función pública) y la propiedad privada (en tanto que instituto organizador de la apropiación, el uso, el disfrute y la disposición sobre el suelo) fue el que condujo a Javier a valorar, mejor que cualquier otro urbanista, la singularidad de la fórmula española para conectar una y otra, para articular la conversión de una determinación pública objetiva en contenido de una situación subjetiva dominical y, sobre todo, para organizar -en el caso de ser precisa la previa transformación urbanística del suelo, es decir, la alteración cualitativa consistente en su pase del estado rústico o no urbano al estado propio de elemento del tejido urbano, es decir, de solar- el proceso técnico, económico y jurídico de la urbanización.

Singularidad, cifrada en una específica combinación entre, de un lado, la afirmación del carácter estatutario del efecto de la ordenación urbanística: la delimitación del contenido (en facultades y deberes) del derecho de propiedad del suelo según su concreta función sociourbanística, y, de otro lado, la entrega de la aludida transformación -cuando ésta no es asumida 
por la Administración- a <<la propiedad >>, es decir, no a todos y cada uno de los propietarios del suelo afectado, sino al conjunto de ellos agrupados forzosamente a tal fin durante el tiempo de duración del proceso y para asegurar el buen resultado de éste.

Es éste de la agrupación forzosa de un efecto más de la vinculación objetiva del suelo al destino determinado por la ordenación según la función social asignada al suelo en cada caso concreto; efecto, que se traduce en la articulación imperativa del conjunto de intereses inmobiliarios afectados $\mathrm{y}$, por tanto, del de los correspondientes titulares de derechos subjetivos en colaboradores forzosos del poder público urbanístico bajo forma asociativa peculiar e inexcusable (bajo sanción de expropiación forzosa, es decir, de exclusión del proceso de transformación) bajo el incentivo-garantía del asimismo peculiar principio de equitativa distribución -en especie, como regla general- de beneficios y cargas.

La conciencia cada vez más acusada de esta singularidad y sus orígenes, de su parcial desactualización en el contexto comunitario-europeo en el que ha de operar, y, por ello, de la marcada exposición al desequilibrio de las piezas y el funcionamiento conforme a los principios informantes a que su complejidad somete el sistema, es la que sin duda condujo a Javier:

- Primero por el camino -antes comentado- del agotamiento de las posibilidades de mejora y puesta al día.

- Luego a defender decididamente sus principios básicos y, en particular, el carácter de función pública de la entera ordenación urbanística cuando -sobre la base de la política emblemática de la integración europea en un mercado común interior y la simplista reducción del urbanismo a sector de la economía- se pusieron en cuestión, en el informe emitido por el Tribunal de defensa de la Competencia, las bases mismas del sistema.

- Y seguidamente, a manifestarse críticamente respecto de los cambios inducidos por la política de <<liberalización>> del urbanismo practicada a partir de 1996; cambios que, bajo capa de simplificación y agilización de los procedimientos administrativos y los mecanismos de planificación y limitación a la introducción del derecho de promoción de actuaciones urbanísticas, ocultaba un verdadero trastocamiento del sistema capaz de diluir la cultura urbanística trabajosamente decantada (como ha demostrado la experiencia).

- Finalmente, a acoger positivamente la innovación autonómica plasmada en la figura del llamado <<urbanizador>>, en cuanto superadora del bloqueo derivado de la identificación entre iniciativa privada y propiedad del suelo. Y ello, sin perjuicio de la crítica de la perversión de la figura por mala aplicación práctica de su configuración legal, propiciada no en último término por el trastocamiento del sistema provocado por la política liberalizadora, según acaba de señalarse. 


\section{La perspectiva comparatista y la contestación del sustancial agotamiento del sistema.}

Los avatares de la vida profesional colocaron a Javier en una posición idónea, primero en el Ministerio hoy de Fomento y luego en el de la Vivienda, para continuar su reflexión desde y con la comparación sistemática del modelo español con otros, fundamentalmente -aunque no sólolos de países comunitario-europeos. Es ésta una fase fructífera de salidas al extranjero, de organización de algún encuentro en España con expertos de otros países y, con los datos y la experiencia adquirida, de impulso de un trabajo comparatista serio.

La mayor perspectiva así adquirida y la riqueza de matices y posibilidades por ella proporcionada abocan en la maduración de la insostenibilidad de la singularidad del sistema propio, siquiera en alguna de sus características más acusadas, o, si se prefiere, de la paulatina decantación de la conclusión del agotamiento del modelo y la necesidad de un cambio profundo que lo sitúe a la altura de los tiempos. Punto culminante de esa maduración es la fijación del decálogo de peculiaridades limitadoras o disfuncionales, que constituye todo un manifiesto y una llamada a la renovación. La dirección de ésta no parecía ofrecer duda: la marcaba, en el sentido de reintegración a la cultura territorial continental europea, la propia deriva de nuestro sistema, resultado de una mezcla explosiva, en los últimos tiempos, del <<rentismo>> de propia raíz con la reducción del urbanismo a mecanismo regulador de la oferta en el mercado del producto inmobiliario-urbano con lógica económico-financiera resistente a otras sensibilidades, en particular la medioambiental.

\section{Hacia una visión integradora y por una ordenación urbanística servidora del valor medioambiental.}

Todo acabó confluyendo cuando Javier se decidió tardíamente a acabar su cursus honorum en la Universidad. El reto que asumió, ya perfectamente pertrechado para ello y al elegir el objeto de su tesis doctoral, es perfectamente congruente con su trayectoria y sus aspiraciones de superar los análisis y progresos parciales y alcanzar la perspectiva del todo en una teoría adecuada. Como también lo es el rigor con el que lo afrontó y que le permitió culminar una obra que asombra. Toda ella desborda voluntad de constitución, sentando sus bases y sus categorías conceptuales, de la ciencia específica y comprensiva desde y con la que abordar adecuadamente la organización de nuestra convivencia en el territorio y de la configuración del espacio propio de dicha convivencia. Naturalmente, desbordando los límites y las limitaciones inherentes a los horizontes parciales de sus mundos respectivos- de las distintas aproximaciones disciplinares -técnica, jurídica, económica, geográfica, sociológica, etc....- a las cuestiones que plantean dichas tareas.

Mas allá de la suerte que le esté deparada en la comunidad científica, es innegable su valor, por lo que en quienes tuvimos el honor de recompensar el ingente esfuerzo personal con la atribución a Javier del grado académico de Doctor tuvimos conciencia de que con ello se estaba reconociendo, al mismo tiempo, su enorme contribución al urbanismo español.

No era propio, sin embargo, de Javier abandonar canteras de trabajo largo tiempo cultivadas y prometedoras de progresos concretos. 
Por ello, prosiguió -directa e indirectamente, alentando a otros- los esfuerzos de mejora y perfeccionamiento de nuestro sistema urbanístico y gobierno del territorio en la línea correcta de su plena congruencia con el orden de valores y principios establecido por el bloque formado por el Derecho originario comunitario-europeo y el Derecho constitucional propio $y$, en particular, con el medio ambiente adecuado y la calidad de vida. Afloraba aquí de nuevo la aspiración de corregir la transformación en curso de dicho sistema en una constantemente renovada operación en la que al hombre acaba por diluírsele -sobre todo en sede de su organización política- toda sensibilidad para su responsabilidad última por su conducta en y para con el mundo. $Y$ en ello estaba cuando hubo de dejarlo por imperativo inapelable, de modo que pudo aún dejarnos un espléndido número monográfico de la revista que dirigía con criterio certero, el relativo a la evaluación ambiental estratégica en la planificación urbana territorial. 